Available online at GSC Online Press Directory

GSC Biological and Pharmaceutical Sciences

e-ISSN: 2581-3250, CODEN (USA): GBPSC2

Journal homepage: https://www.gsconlinepress.com/journals/gscbps

(CASE STUDY ARTICLE)

\title{
Completeness of filling medical record documents on inpatient ward, Ungaran General Hospital-Semarang, Central Java -Indonesia
}

\author{
Lestari Wiji ${ }^{1}$, Astuti Retno ${ }^{1}$ and Isworo Slamet ${ }^{2, *}$ \\ ${ }^{1}$ Medical Record Study Program, Faculty of Health, Dian Nuswantoro University, Semarang. \\ ${ }^{2}$ Environmental Health Study Program, Faculty of Health, Dian Nuswantoro University, Semarang.
}

Publication history: Received on 04 July 2020; revised on 11 July 2020; accepted on 13 July 2020

Article DOI: https://doi.org/10.30574/gscbps.2020.12.1.0209

\begin{abstract}
Ungaran Hospital is a type C referral hospital in Semarang regency, therefore it must have excellent and good service, including services for patients and patient's regularity medical records. The mechanism for filling out medical record documents is often a barrier to services which results in a delayed return of medical record documents. This study aims to determine the effectiveness of filling medical record documents in 8 wards, in January - February 2020. The purpose of this study: This study aims to determine the incompleteness of filling medical record documents which result in delays in submitting medical record documents to the assembly unit. This research was conducted from February to March 2020, with the type of descriptive research that is interviews and observations of medical records officers. The results of the study were based on the calculation of 30 medical record documents consisting of 15 inpatient medical record documents and 15 outpatient medical record documents, the checklist table used to determine the completeness of filling medical record documents. Based on the analysis of medical record documents on hospitalization which includes a review of identification, reporting, authentication, and recording of 30 medical record documents studied there were 28 complete medical record documents and 2 incomplete medical records. It is necessary to provide guidance to doctors/nurses considering the importance of completeness of the contents of medical record documents in accordance with the conditions or needs of patients.
\end{abstract}

Keywords: Quantitative analysis; Assembling; Medical record documents; Services; Returning documents

\section{Introduction}

A hospital is a health service institution that conducts complete individual health services that provide inpatient, outpatient, and emergency services. In the process of serving patients, a medical support unit is needed so that it runs well and comprehensively. (1) The Medical Records Department is a medical support unit and is an important part in assisting the delivery of services to patients in the hospital, especially in the management of documents and medical records of patients in the processes carried out in health care. These records are very important in the service for patients because with complete data can provide information in making decisions both treatment, treatment, medical action.[2].

Ungaran Regional General Hospital is a hospital-owned by the Semarang Regency Government which is a referral hospital for all community health centers in the Semarang regency. In improving hospital services as a place of reference, it has made various efforts to improve services and medical support. The Medical Records Department is a medical and non-medical support service unit which is an integral activity of the overall Hospital service that supports the success of hospital services [3]

\footnotetext{
${ }^{*}$ Corresponding author: Isworo Slamet
} 
The medical record department is a section that aims to create an orderly condition for the administration of Medical Record documents so that they can support efforts to improve health services in the hospital, without the support of a good medical record management system, so there will not be an orderly administration of hospital documents [4] The medical record department has a work unit that is the assembling unit tasked with receiving medical record documents with a daily census of the care ward which is then recorded in the expedition book, checking the contents of the medical record documentation, rearranging the medical record file in the order specified, examining the incompleteness of the medical record document medical, controlling the use of medical record numbers and entering documents that have been assembled into the hospital information system. Medical record data processing activities include assembling, indexing coding, filing and analyzing reporting [5].

The assembling unit is a medical records department supporting unit that is in charge of managing medical record documents from the room to the medical record department. The procedure for submitting medical record documents from the room is the procedure for submitting medical record files for patients who have returned and recovered, the patient's medical record documents are completely filled and submission with expedition book within 24 hours [5] [6]. Assembling section medical records officer has the task of taking inpatient medical records file from each ward/inpatient room, taking medical records documents of patients who have returned home, recording expedition books and checking the completeness of medical record documents, submitting medical record documents that are has been assembled to the inpatient indexing coding section [7]

The incompleteness of medical record documents can be caused by the lack of discipline of medical personnel and paramedics to complete the patient's medical records. Many factors include, among others, doctors prioritizing providing services, the number of patients so that doctors try to provide services quickly, doctors are still waiting for the results of laboratory examinations to better ensure a more specific diagnosis, a limited number of doctors, lack of cooperation between nurses and medical record officers and doctors are less concerned about medical records. [8]. Because of the importance of completeness of filing medical record files, the study aims to examine the causes of incompleteness in filing patient medical record files.

\section{Methods}

This research use desciptive qualitative approach. The qualitative research is done because researchers want to explore phenomena that cannot be quantified that are descriptive [9]. A cross sectional approach is a study conducted with momentary observations in a certain period and each subject of the study was only made once during the study. The population in this study is the medical record file [10]. The sample in this study was 30 files that were incomplete filling in February-March 2020, as follows: Review of identification of inpatient medical record documents in the period of February - March 2020, review of reporting of inpatient medical record documents in the February-2020 period, review of inpatient medical record document authentication in the February - March 2020 period, review of inpatient medical record document records in the February - March 2020 period, the observed population is the number of inpatient medical record documents in public hospitals in the February month period - March 2020 as many as 30 documents of medical record instruments used are check list tables to find out whether or not filling in the medical record file. The subjects in this study were 1 employee of the asemebling unit who served in the medical record. Data collection in this study will use interview and observation methods. This method is used to explore research subjects to determine the incompleteness of filling medical record files.

\section{Results and discussion}

The implementation of medical record management and health information at Ungaran General Hospital covers the standard operating procedure in the assembling section, which is the operational standard for the delivery of medical record documents from inpatient rooms to patients who have returned to the medical record department (assembling unit). Medical records must be completely filled out, accompanied by an expedition book, delivered within a maximum of $2 \times 24$ hours at 10:00 am.

Medical records from standard operating procedures at Ungaran general hospital were approved by the Director of Ungaran general hospital No. Document 018 / L / X / 2015 on September 1, 2018. Standard Operating Procedures regulate the procedure for checking the completeness of medical record documents (hospital entry and exit forms), cover letters for sick people, surgery action sheets, anesthesia action sheets, death letter statements (if the patient dies), clarification of medical records received, accompanied by an expedition book from the treatment room, medical return records if the document is incomplete, complete documents are then signed on the expedition book, validating medical record documents in the patient admission book for patients who have recovered / return home, check the 
completeness of medical record documents, submit complete medical record documents to the code department by using the expedition book as a control, check health facilities (social security administrator for health) before sending to the encoding section and combining indexing with social security administrators for health document claims. In the assembling section there is only one medical record officer with the main task of reviewing the forms, if there are several unused forms, the formulis will be revised, the officer performs the assembling process on the medical record file for inpatients, if there are incomplete forms then they will be separated first then immediately see the nurse / doctor concerned to complete the blank or incomplete part, the complete medical record file then immediately submit the medical record documents that have been assembled to the inpatient indexing coding section. The Assembling process is only carried out on the inpatient patient medical record file, which is a summary of the patient's history in the clinic, outpatient initial assessment, integrated patient development notes, laboratory examination results form, a prescription copy attachment form and a patient certificate attachment form. After the patient leaves the medical record document in the ward section is submitted by the nurse to the assembling section by bringing an expedition book to hand over the medical record documentation. Then do the assembly of forms and arrange the forms in the order that starts from RM 01 to the next. However, for the assembly of the outpatient form the assembly process is not carried out, but only transfers the outpatient form to the inpatient form.

The patient form at the Ungaran general hospital consists of an outpatient form and an inpatient form, as follows: The outpatient form includes 1. RM 17 / IRJ / PRWT / Rev 00: Summary of Polyclinic History. 2. RM 18 / IRJ / PRWT / Rev 00: Initial assessment of outpatient nursing. 3. RM.0 4. B / IRJ / IRJ / DPJP.PPA / Rev 00: Outpatient inspection results with integrity. 4. RM 19 / IRJ / DPJP.PPA / PPA / Rev 00: Initial outpatient assessment. 5. IRJ Form: Results of laboratory tests. 6. IRJ Form: Paste a copy of the recipe. 7. IRJ Form: Attachment of correspondence letter. Inpatient form includes 1. RM 01: Entry and exit sheets. 2. RM 23.B / IRI / DPJP / Rev page 2/2: Physical examination. 3. RM 23.A / IRI / DPJP / Rev: Nursing planning. 4. RM 01.B / IRI / TPPRI / Patient. Rev p. 1/1: General consent. 5. Inpatient Acceptance Checklist (RM 10). 6. RM 02.A / IRI / DPJP / PPJP / Rev 00 page 1/3: Inpatient assessment form. 7. RM 02.A / IRI / DPJP / PPJP / Rev 00 page 2/3: General inspection. 8. RM 02.A / IRI / DPJP / PPJP / Rev 00 page 3/3: General inspection. 9. RM 02.B / IRI / DPJP / PPJP / Rev 01 pg 1-5: Inpatient nursing assessment. 10. RM 04.A / IRI / DPJP / PPJP / PPA / Rev 00: Integrated notes. 11. RM 05 / IRI / Professional / Rev 00: Graph. 12. RM 07 / IRI / PPJP / Rev 00: Nursing record. 12. RM 08 / IRI / PPJP / Rev 00: Resume of patients going home. 13. RM 11.C / IRI / PPJP / Rev 00: Initial assessment of pain. 14. Form 34: Drug reconciliation. 15. RM 09 / IRI / PPJP / Rev 00: Nursing resume. 16. RM 27 / DPJP / PPJP / Rev 00: Notes on the implementation of patient education go home page 1/3. 17. IRJ Form: Laboratory tests. 18. IRJ Form: A copy of the recipe. 19. IRJ Form: Social security administrator for health correspondence letter.

\subsection{The completeness Analysis}

The comprehensive analysis aims to make complete and continuous medical records to protect the legal interests of patients, doctors, and hospitals, including quantitative analysis and qualitative analysis [11]

The Quantitative Analysis (analysis of incompleteness of medical record documents) is a review of certain parts of the contents of medical records with the intention of finding specific deficiencies related to recording medical records include is: [12]

- Identity review: Check the patient's identity on each sheet of medical record document. On each sheet of medical records, there must be a patient identity (No. the medical record and the name of the patient), if there is an anonymous sheet that must be reviewed to determine the owner of the form..

- Review authentication. In this component, the medical record officer will check the authentication of the recording in the form of a signature, clear name including the stamp or code of someone on the hospital information system, in writing a clear name there must be a title or professional title (doctor, nurse). In the authentication process, it should not be signed by anyone other than the author, except if it is written by the doctor on duty then there is the author's signature plus countersign by the room supervisor and written by the review. The authentication review is carried out on instructions from whom or who has been verified by whom or agreed by whom.

- Recording Review. Checks on records are incomplete or cannot be read, so they can be completed and clarified. if there is something wrong in the recording, the wrong part is given a statement beside it that the note is wrong.

- Reporting Review. This component includes checking reports from service activities, important recording hours reports are recorded as they relate to regulations such as patient history sheets and physical examinations. So you can calculate the IMR (Incomplete Medical Record) as follows (13) : 


$$
I M R=\frac{\text { Number of incomplete documents }}{\text { Number of documents examined }} \times 100
$$

$=(2 / 30) \times 100$

$=7 \%$, the number of incomplete documents is $7 \%$.

The incomplete control of medical record documents is only in the inpatient document which involves all health care providers, such as doctors, nurses, nutrition, and pharmacy. The incompleteness of filling out medical record documents is adjusted with quantitative analysis, namely identification, recording, reporting, and authentication. By reviewing the incomplete form sheet then contact the nurse/doctor providing the service to complete the form to be complete (14). There are no operational standards for quality procedures in assembly at hospitals, but there are policies governing assembly, including 1 . Time to return medical records from the treatment room to the assembly unit no later than 10 am (2x24 hours). 2. For baby medical records included in the assembly must be combined with maternal medical records. 3. Medical records for patients using social security administrators for health facilities must be filed as a part of the patient's medical record. The results of the quantitative analysis of the identification review of the medical record document - Inpatient Hospital Ungaran Period February - March 2020, as follows:

Table 1 Review Identification (15)

\begin{tabular}{llllll}
\hline Ward & Complete & \multicolumn{3}{l}{ Incomplete } & Total \\
\hline & $\Sigma$ & $\%$ & $\Sigma$ & $\%$ & $\Sigma$ \\
The Jasmine ward & 4 & $100 \%$ & 0 & $0 \%$ & 4 \\
The Orchid ward & 4 & $100 \%$ & 0 & $0 \%$ & 4 \\
The Cempaka ward & 4 & $100 \%$ & 0 & $0 \%$ & 4 \\
The Dahlia ward & 4 & $100 \%$ & 0 & $0 \%$ & 4 \\
The Rose ward & 4 & $100 \%$ & 0 & $0 \%$ & 4 \\
The Flamboyant ward & 4 & $100 \%$ & 0 & $0 \%$ & 4 \\
The Perinatology ward & 3 & $100 \%$ & 0 & $0 \%$ & 3 \\
The ICU ward & 3 & $100 \%$ & 0 & $0 \%$ & 3 \\
TOTAL & 30 & $100 \%$ & 0 & $0 \%$ & 30 \\
\hline
\end{tabular}

Quantitative analysis results show that for the review of inpatient medical record identification documents at Ungaran General Hospital, from the 30 medical record documents studied, the results obtained are 30 complete medical record documents $(100 \%)$ and 0 incomplete medical record documents $(0 \%)$. Completeness in filling in the patient's identity (No. Medical record etc. in the patient's name) because this medical officer at the Ungaran general hospital understands the importance of completing medical record documents.

Quantitative analysis of the review of inpatient medical record documents (RM-RI) Ungaran general hospital period February - March 2020.

The quantitative analysis results show that for review of inpatient medical record documents reporting at Ungaran General Hospital, from the 30 documented medical records studied, 29 (96\%) were complete and $1(3 \%)$ incomplete, namely at RM 1 (Medical Record 1) incompleteness was identified in the main diagnosis, especially in filling medical record documents in the jasmine ward as much as $1(75 \%)$ this is because the relevant medical staff did not understand the importance of completeness in filling outpatient medical record documents.

Quantitative analysis of authentication review of medical records-inpatient record (RM-RI) Ungaran general hospital period February - March 2020 [16] 
Table 2 Review Reporting

\begin{tabular}{lcllll}
\hline Ward & \multicolumn{2}{c}{ Complete } & \multicolumn{2}{l}{ Incomplete } & Total \\
\hline & $\Sigma$ & $\mathbf{\%}$ & $\boldsymbol{\Sigma}$ & $\mathbf{\%}$ & $\Sigma$ \\
\hline The Jasmine ward & 3 & $75 \%$ & 1 & $25 \%$ & 4 \\
The Orchid ward & 4 & $100 \%$ & 0 & $0 \%$ & 4 \\
The Cempaka ward & 4 & $100 \%$ & 0 & $0 \%$ & 4 \\
The Dahlia ward & 4 & $100 \%$ & 0 & $0 \%$ & 4 \\
The Rose ward & 4 & $100 \%$ & 0 & $0 \%$ & 4 \\
The Flamboyant ward & 4 & $100 \%$ & 0 & $0 \%$ & 4 \\
The Perinatology ward & 3 & $100 \%$ & 0 & $0 \%$ & 3 \\
The ICU ward & 3 & $100 \%$ & 0 & $0 \%$ & 3 \\
TOTAL & 29 & $96 \%$ & 1 & $3 \%$ & 30 \\
\hline
\end{tabular}

Results of the quantitative analysis showed that for the review of inpatient medical record document authentication at the General Hospital of Ungaran, from the 30 medical record documents studied, 29 (96\%) complete status, and 1 (3\%) incomplete status were obtained. Inadequate filling of medical record documents occurred in cempaka wards $=1$ $(25 \%)$. The incomplete document status occurs because there is no sign of the patient's responsible doctor. This is caused due to busy doctors and nurses who do not understand the importance of completeness of medical record documents.

Quantitative analysis review of records of medical records - Inpatients (DRM-RI) general hospital Ungaran period February - March 2020 (17)

Table 3 Review of Authentication

\begin{tabular}{llllll}
\hline Ward & Complete & \multicolumn{2}{c}{ Incomplete } & Total \\
\hline & $\Sigma$ & $\mathbf{\%}$ & $\boldsymbol{\Sigma}$ & $\mathbf{\%}$ & $\Sigma$ \\
\hline The Jasmine ward & 4 & $100 \%$ & 0 & $0 \%$ & 4 \\
The Orchid ward & 4 & $100 \%$ & 0 & $0 \%$ & 4 \\
The Cempaka ward & 3 & $75 \%$ & 1 & $25 \%$ & 4 \\
The Dahlia ward & 4 & $100 \%$ & 0 & $0 \%$ & 4 \\
The Rose ward & 4 & $100 \%$ & 0 & $0 \%$ & 4 \\
The Flamboyant ward & 4 & $100 \%$ & 0 & $0 \%$ & 4 \\
The Perinatology ward & 3 & $100 \%$ & 0 & $0 \%$ & 3 \\
The ICU ward & 3 & $100 \%$ & 0 & $0 \%$ & 3 \\
TOTAL & 29 & $96 \%$ & 1 & $3 \%$ & 30 \\
\hline
\end{tabular}


Table 4 Recording Review

\begin{tabular}{llllll}
\hline Ward & \multicolumn{2}{c}{ Complete } & \multicolumn{2}{c}{ Incomplete } & Total \\
\hline & $\Sigma$ & $\%$ & $\Sigma$ & $\%$ & $\Sigma$ \\
\hline Melati & 4 & $100 \%$ & 0 & $0 \%$ & 4 \\
The Jasmine ward & 4 & $100 \%$ & 0 & $0 \%$ & 4 \\
The Orchid ward & 4 & $100 \%$ & 0 & $0 \%$ & 4 \\
The Cempaka ward & 4 & $100 \%$ & 0 & $0 \%$ & 4 \\
The Dahlia ward & 4 & $100 \%$ & 0 & $0 \%$ & 4 \\
The Rose ward & 4 & $100 \%$ & 0 & $0 \%$ & 4 \\
The Flamboyant ward & 3 & $100 \%$ & 0 & $0 \%$ & 3 \\
The Perinatology ward & 3 & $100 \%$ & 0 & $0 \%$ & 3 \\
The ICU ward & 30 & $100 \%$ & 0 & $0 \%$ & 30 \\
Total & & & & & \\
\hline
\end{tabular}

Quantitative analysis results show that for reviewing inpatient medical record documents in general hospitals Ungaran from 30 medical record documents studied obtained 30 medical records documents (100\%) with good writing and 0 $(0 \%)$ with poor writing Evaluation of the compliance and performance of assembling officers in receiving a return of medical record documents to the assembling section with observations made 30 times of service activities based on hospital internal standards namely input standards, standard operating procedures, minimum service standard delays [14] Standards of the results of evaluations of the compliance and performance of assembling officers are as follows :

Table 5 Evaluation results of 30 service activities

\begin{tabular}{|c|c|c|c|}
\hline \multirow[t]{2}{*}{ No } & \multirow[t]{2}{*}{ Description of activities. } & \multicolumn{2}{|c|}{ Information } \\
\hline & & Yes & No \\
\hline 1 & $\begin{array}{l}\text { Does the assembling officer receive the return of all patient's Medical } \\
\text { Record documents home within } 2 \times 24 \text { hours? }\end{array}$ & $\sqrt{ }$ & \\
\hline 2 & $\begin{array}{l}\text { Does the assembling officer examine the completeness of the Medical } \\
\text { Record of the patient going home both quantitative and qualitative? }\end{array}$ & $\sqrt{ }$ & \\
\hline 3 & $\begin{array}{l}\text { Does the assembling officer record incomplete Medical Record documents } \\
\text { and return them to the room clerk? }\end{array}$ & $\sqrt{ }$ & \\
\hline 4 & $\begin{array}{l}\text { Are the Medical Record documents complete within } 7 \text { days after the } \\
\text { patient returns? }\end{array}$ & $\sqrt{ }$ & \\
\hline 5 & $\begin{array}{l}\text { Is the list of late medical record documents sent to the Head of the room } \\
\text { and copied to the Medical Records Committee and Medical Committee? }\end{array}$ & $\sqrt{ }$ & \\
\hline 6 & $\begin{array}{l}\text { Does the officer report to the medical committee to further be reported to } \\
\text { the Director regarding medical records that have not yet returned or are } \\
\text { incomplete? }\end{array}$ & $\sqrt{ }$ & \\
\hline 7 & $\begin{array}{l}\text { Did the officer get a warning from the head to immediately fill out and } \\
\text { complete the medical record? }\end{array}$ & $\sqrt{ }$ & \\
\hline 7 & $\begin{array}{l}\text { Does the officer receive administrative sanctions if within } 14 \text { days of the } \\
\text { warning the Director of the medical record has not returned in its } \\
\text { complete condition? }\end{array}$ & $\sqrt{ }$ & \\
\hline
\end{tabular}

The quantitative and qualitative analysis of 30 cases consisting of 15 inpatient cases and 15 outpatient cases. 


\subsection{Quantitative and qualitative analysis of 15 inpatient medical record documents}

Completeness of medical record documents must be completed within $2 \times 24$ hours if there are still deficiencies in the document then it is called DMR (Delinquent Medical Record), [18] Quantitative analysis is the result of identifying the patient's social status, a correction note for writing errors with a one-time cross and the initials of the person responsible, ie authentication, the signature of the doctor responsible with the name and time, and the reporting must be in accordance with operational standards at the Ungaran general hospital. While the qualitative analysis includes a review of the completeness, recording, and consistency of the diagnosis, a review of actions, approval based on information, and a review of compensation risks.

The results of the analysis of 15 medical record documents for inpatients carried out quantitative analysis with identification review, authentication review, recording review and review reporting on the contents of each form sheet obtained by completing medical record documents as many as 15 medical record documents. The quantitative recapitulation results of 15 inpatient medical record documents with results (13/15) x 100\% = 86.6\% because of the 15 medical record documents there are 2 medical record documents which are incomplete and cannot be read clearly. While the results of the analysis of 15 medical records of inpatients were carried out qualitative analysis with a consistency review of identity recording, a review of the consistency of recording the main diagnoses, a review of the consistency of informed consent, a review of matters that could potentially cause harm to the results (15/15) X 100\% $=100 \%$ complete)

Table 6 Recapitulation of quantitative analysis of medical record documents

\begin{tabular}{|c|c|c|c|c|c|c|c|c|c|}
\hline \multirow{2}{*}{$\begin{array}{l}\text { No. } \\
\text { Medical } \\
\text { record }\end{array}$} & \multicolumn{2}{|c|}{ Identification } & \multicolumn{2}{|c|}{ Recording } & \multicolumn{2}{|c|}{ Reporting } & \multicolumn{2}{|c|}{ Authentication } & \multirow[t]{2}{*}{ Information } \\
\hline & $\mathbf{C}$ & I & C & $\mathbf{I}$ & $\mathbf{C}$ & $\mathbf{I}$ & C & $\mathbf{I}$ & \\
\hline $1658 X X$ & $\sqrt{ }$ & & $\sqrt{ }$ & & $\sqrt{ }$ & & $\sqrt{ }$ & & Complete \\
\hline $1635 X X$ & $\sqrt{ }$ & & $\sqrt{ }$ & & $\sqrt{ }$ & & & $\sqrt{ }$ & The doctor did not sign \\
\hline $1645 X X$ & $\sqrt{ }$ & & $\sqrt{ }$ & & $\sqrt{ }$ & & $\sqrt{ }$ & & Complete \\
\hline $1670 x x$ & $\sqrt{ }$ & & $\sqrt{ }$ & & & $\sqrt{ }$ & $\sqrt{ }$ & & $\begin{array}{l}\text { The diagnosis is } \\
\text { illegiblea }\end{array}$ \\
\hline 1474XX & $\sqrt{ }$ & & $\sqrt{ }$ & & $\sqrt{ }$ & & $\sqrt{ }$ & & Complete \\
\hline $1290 X X$ & $\sqrt{ }$ & & $\sqrt{ }$ & & $\sqrt{ }$ & & $\sqrt{ }$ & & Complete \\
\hline $1660 X X$ & $\sqrt{ }$ & & $\sqrt{ }$ & & $\sqrt{ }$ & & $\sqrt{ }$ & & Complete \\
\hline 1480XX & $\sqrt{ }$ & & $\sqrt{ }$ & & $\sqrt{ }$ & & $\sqrt{ }$ & & Complete \\
\hline $1665 X x$ & $\sqrt{ }$ & & $\sqrt{ }$ & & $\sqrt{ }$ & & $\sqrt{ }$ & & Complete \\
\hline 0340XX & $\sqrt{ }$ & & $\sqrt{ }$ & & $\sqrt{ }$ & & $\sqrt{ }$ & & Complete \\
\hline $1575 X X$ & $\sqrt{ }$ & & $\sqrt{ }$ & & $\sqrt{ }$ & & $\sqrt{ }$ & & Complete \\
\hline $1187 X X$ & $\sqrt{ }$ & & $\sqrt{ }$ & & $\sqrt{ }$ & & $\sqrt{ }$ & & Complete \\
\hline 0975XX & $\sqrt{ }$ & & $\sqrt{ }$ & & $\sqrt{ }$ & & $\sqrt{ }$ & & Complete \\
\hline 1639XX & $\sqrt{ }$ & & $\sqrt{ }$ & & $\sqrt{ }$ & & $\sqrt{ }$ & & Complete \\
\hline $1697 X X$ & $\sqrt{ }$ & & $\sqrt{ }$ & & $\sqrt{ }$ & & $\sqrt{ }$ & & Complete \\
\hline 1650XX & $\sqrt{ }$ & & $\sqrt{ }$ & & $\sqrt{ }$ & & $\sqrt{ }$ & & Complete \\
\hline 1645XX & $\sqrt{ }$ & & $\sqrt{ }$ & & $\sqrt{ }$ & & $\sqrt{ }$ & & Complete \\
\hline 1649XX & $\sqrt{ }$ & & $\sqrt{ }$ & & $\sqrt{ }$ & & $\sqrt{ }$ & & Complete \\
\hline 1665XX & $\sqrt{ }$ & & $\sqrt{ }$ & & $\sqrt{ }$ & & $\sqrt{ }$ & & Complete \\
\hline 1685XX & $\sqrt{ }$ & & $\sqrt{ }$ & & $\sqrt{ }$ & & $\sqrt{ }$ & & Complete \\
\hline 1688XX & $\sqrt{ }$ & & $\sqrt{ }$ & & $\sqrt{ }$ & & $\sqrt{ }$ & & Complete \\
\hline
\end{tabular}




\begin{tabular}{llllll}
$1683 \mathrm{XX}$ & $\sqrt{ }$ & $\sqrt{ }$ & $\sqrt{ }$ & $\sqrt{ }$ & Complete \\
$1643 \mathrm{XX}$ & $\sqrt{ }$ & $\sqrt{ }$ & $\sqrt{ }$ & $\sqrt{ }$ & Complete \\
$1177 \mathrm{XX}$ & $\sqrt{ }$ & $\sqrt{ }$ & $\sqrt{ }$ & $\sqrt{ }$ & Complete \\
$1525 \mathrm{XX}$ & $\sqrt{ }$ & $\sqrt{ }$ & $\sqrt{ }$ & $\sqrt{ }$ & Complete \\
$1671 \mathrm{XX}$ & $\sqrt{ }$ & $\sqrt{ }$ & $\sqrt{ }$ & $\sqrt{ }$ & Complete \\
$1600 \mathrm{XX}$ & $\sqrt{ }$ & $\sqrt{ }$ & $\sqrt{ }$ & $\sqrt{ }$ & Complete \\
$1640 \mathrm{XX}$ & $\sqrt{ }$ & $\sqrt{ }$ & $\sqrt{ }$ & $\sqrt{ }$ & Complete \\
$1651 \mathrm{XX}$ & $\sqrt{ }$ & $\sqrt{ }$ & $\sqrt{ }$ & $\sqrt{ }$ & Complete \\
$1690 \mathrm{XX}$ & $\sqrt{ }$ & $\sqrt{ }$ & $\sqrt{ }$ & $\sqrt{ }$ & Complete \\
\hline Total & & & & $93 \%$ \\
\hline
\end{tabular}

\subsection{Quantitative and qualitative analysis of 15 outpatient medical record documents}

The procedure for completing outpatient medical record documents is the same as the procedure for completing inpatient medical record documents. The results of the analysis of 15 outpatient medical record documents were carried out quantitative analysis with identification review, authentication review, recording review and reporting review on the contents of each form sheet obtained completeness of medical record documents as many as 15 medical record documents. From the quantitative recapitulation results 15 outpatient medical record documents are (15 / 15) $\mathrm{x} 100 \%=100 \%$, because all reviews are complete and the documents are well read.

The results of the analysis of 15 medical records of outpatients performed a qualitative analysis similar to inpatient procedures, namely the consistency review of identity recording, review of the consistency of recording the main diagnosis, review of informed consent consistency, review of things that could potentially cause harm. From each form sheet, 15 medical record documents were obtained. The results of the qualitative recapitulation of 15 outpatient medical record documents are (15/15) $\mathrm{x} 100 \%=100 \%$ complete because in outpatients no action is taken so there is informed consent.

Table 7 Recapitulation of qualitative analysis of medical record documents

\begin{tabular}{|c|c|c|c|c|c|c|c|c|c|}
\hline & \multirow[t]{3}{*}{ No RM } & \multirow{2}{*}{\multicolumn{2}{|c|}{$\begin{array}{l}\text { Consistency } \\
\text { Pencatatan } \\
\text { Identitas }\end{array}$}} & \multirow{2}{*}{\multicolumn{2}{|c|}{$\begin{array}{l}\text { Recording Consistency } \\
\text { Diagnosa Utama }\end{array}$}} & \multirow{2}{*}{\multicolumn{2}{|c|}{$\begin{array}{l}\text { Consistency } \\
\text { Informed Consent }\end{array}$}} & \multirow{2}{*}{\multicolumn{2}{|c|}{$\begin{array}{l}\text { Potential } \\
\text { Losses }\end{array}$}} \\
\hline & & & & & & & & & \\
\hline & & $\mathbf{K}$ & TK & $\mathbf{K}$ & TK & $\mathbf{K}$ & TK & Yes & No \\
\hline 1 & $1658 X X$ & $\sqrt{ }$ & & $\sqrt{ }$ & & $\sqrt{ }$ & & & $\sqrt{ }$ \\
\hline 2 & $1635 X X$ & $\sqrt{ }$ & & $\sqrt{ }$ & & $\sqrt{ }$ & & & $\sqrt{ }$ \\
\hline 3 & $1645 X X$ & $\sqrt{ }$ & & $\sqrt{ }$ & & $\sqrt{ }$ & & & $\sqrt{ }$ \\
\hline 4 & $1670 X X$ & $\sqrt{ }$ & & $\sqrt{ }$ & & $\sqrt{ }$ & & & $\sqrt{ }$ \\
\hline 5 & $1474 X X$ & $\sqrt{ }$ & & $\sqrt{ }$ & & $\sqrt{ }$ & & & $\sqrt{ }$ \\
\hline 6 & 1290XX & $\sqrt{ }$ & & $\sqrt{ }$ & & $\sqrt{ }$ & & & $\sqrt{ }$ \\
\hline 7 & 1660XX & $\sqrt{ }$ & & $\sqrt{ }$ & & $\sqrt{ }$ & & & $\sqrt{ }$ \\
\hline 8 & 1480XX & $\sqrt{ }$ & & $\sqrt{ }$ & & $\sqrt{ }$ & & & $\sqrt{ }$ \\
\hline 9 & $1665 X X$ & $\sqrt{ }$ & & $\sqrt{ }$ & & $\sqrt{ }$ & & & $\sqrt{ }$ \\
\hline 10 & 0340XX & $\sqrt{ }$ & & $\sqrt{ }$ & & $\sqrt{ }$ & & & $\sqrt{ }$ \\
\hline 11 & $1575 X X$ & $\sqrt{ }$ & & $\sqrt{ }$ & & $\sqrt{ }$ & & & $\sqrt{ }$ \\
\hline 12 & 1187XX & $\sqrt{ }$ & & $\sqrt{ }$ & & $\sqrt{ }$ & & & $\sqrt{ }$ \\
\hline 13 & 0975XX & $\sqrt{ }$ & & $\sqrt{ }$ & & $\sqrt{ }$ & & & $\sqrt{ }$ \\
\hline
\end{tabular}




\begin{tabular}{|c|c|c|c|c|c|}
\hline 14 & 1639XX & $\sqrt{ }$ & $\sqrt{ }$ & $\sqrt{ }$ & $\sqrt{ }$ \\
\hline 15 & $1697 X X$ & $\sqrt{ }$ & $\sqrt{ }$ & $\sqrt{ }$ & $\sqrt{ }$ \\
\hline 16 & 1650XX & $\sqrt{ }$ & $\sqrt{ }$ & $\sqrt{ }$ & $\sqrt{ }$ \\
\hline 17 & $1645 X X$ & $\sqrt{ }$ & $\sqrt{ }$ & $\sqrt{ }$ & $\sqrt{ }$ \\
\hline 18 & 1649XX & $\sqrt{ }$ & $\sqrt{ }$ & $\sqrt{ }$ & $\sqrt{ }$ \\
\hline 19 & 1665XX & $\sqrt{ }$ & $\sqrt{ }$ & $\sqrt{ }$ & $\sqrt{ }$ \\
\hline 20 & 1685XX & $\sqrt{ }$ & $\sqrt{ }$ & $\sqrt{ }$ & $\sqrt{ }$ \\
\hline 21 & 1688XX & $\sqrt{ }$ & $\sqrt{ }$ & $\sqrt{ }$ & $\sqrt{ }$ \\
\hline 22 & 1683XX & $\sqrt{ }$ & $\sqrt{ }$ & $\sqrt{ }$ & $\sqrt{ }$ \\
\hline 23 & 1643XX & $\sqrt{ }$ & $\sqrt{ }$ & $\sqrt{ }$ & $\sqrt{ }$ \\
\hline 24 & 1177XX & $\sqrt{ }$ & $\sqrt{ }$ & $\sqrt{ }$ & $\sqrt{ }$ \\
\hline 25 & $1525 X X$ & $\sqrt{ }$ & $\sqrt{ }$ & $\sqrt{ }$ & $\sqrt{ }$ \\
\hline 26 & 1671XX & $\sqrt{ }$ & $\sqrt{ }$ & $\sqrt{ }$ & $\sqrt{ }$ \\
\hline 27 & $1600 X X$ & $\sqrt{ }$ & $\sqrt{ }$ & $\sqrt{ }$ & $\sqrt{ }$ \\
\hline 28 & $1640 X X$ & $\sqrt{ }$ & $\sqrt{ }$ & $\sqrt{ }$ & $\sqrt{ }$ \\
\hline 29 & 1651XX & $\sqrt{ }$ & $\sqrt{ }$ & $\sqrt{ }$ & $\sqrt{ }$ \\
\hline \multirow[t]{2}{*}{30} & 1690XX & $\sqrt{ }$ & $\sqrt{ }$ & $\sqrt{ }$ & $\sqrt{ }$ \\
\hline & Total & & & & 100 \\
\hline
\end{tabular}

The general medical record hospital department of ungaran generally does not use information technology, in the assembling section records or recaps incompleteness manually then submitted to the Incompleteness of Medical Records Completeness section (19) dan kemudian bagian tersebut merekap secara komputerisasi. Reports generated are reports of medical records documents that return to assembling, reports on the number of medical record documents that have been assembled, reports on the number of medical record documents that are incomplete. [20].

Solutions and steps to solve the problem are making standard operating procedures about inpatient medical record documents and standard operating procedures for emergency units, making standard operating procedures about filing medical records page 8 (RM-8) and operating report sheets, making operational standards handling procedures for returning documents late from the room to the medical records section, socializing standard operating procedures to doctors/nurses, setting and ratifying standard operating procedures by the hospital director regarding delays in medical record documents and incomplete forms and then socializing procedures for completing medical record documents. According to the patient's condition or needs. Standard Operating Procedures include warning or reprimand to violating medical personnel, evaluation after socialization is carried out to all relevant sections, forming a team of officers/porters who specifically take medical records to the ward, make a control card. The action plan is expected to be able to correct the problem of delay in returning medical record documents to the assembling unit so that it can be minimized, sustainable, in accordance with the standard operating procedures specified.

\section{Conclusion}

Officers in the assembling unit in the medical record installation at Ungaran General Hospital have done their jobs well, are responsible and in accordance with standard operating procedures. Every medical record document received in the assembling section is always recorded in the expedition book, returning the medical record document if it is incomplete. Changes in activities that are not in accordance with operational standards, namely nurses in the room do not complete the form that is required, doctors or nurses do not fill out the RM-8 (medical records page 8) and the operation report sheet, delay in returning the incomplete medical record documents.

Analysis of inpatient medical record documents that include a review of identification, reporting, authentication, and recording. The observations identified 30 medical record documents studied there were 28 complete medical record documents and 2 incomplete medical records. 


\section{Compliance with ethical standards}

\section{Acknowledgments}

The author is very grateful to the leadership and staff of Ungaran General Hospital and Dian Nuswantoro University so that this research can be carried out well.

\section{Disclosure of conflict of interest}

All authors have stated that this activity is research with no interest in competing.

\section{References}

[1] Ambarriani AS. (2014). Hospital financial performance in the Indonesian national health insurance era. Review of Integrative Business and Economics Research, 4(1), 121-33.

[2] Miller RH and Sim I. (2004). Physicians' use of electronic medical records: barriers and solutions. Health affairs, 23(2), 116-26.

[3] Slamet Nur F and Mukeri AF. (2015). Analysis tangibles, reliability, responsiveness, empathy assurance and image of hospital and interest back to use the service general hospital of poly Ungaran. Journal of Management. $1(1)$.

[4] Lekha L. (2017). Summary of procedures done-work book. SCTIMST.

[5] Bhat S, Gijo EV and Jnanesh NA. (2016). Productivity and performance improvement in the medical records department of a hospital. International Journal of Productivity and Performance Management.

[6] Slaughter A. (2017). Low Adoption Rates of Electronic Medical Records Systems: A Qualitative Study. University of Phoenix.

[7] Ningsih ER, Isa M, Marlinae L, Arifin S and Soediono JB. (2018). Quality of medical record document management system in banjarmasin Islamic Hospital Installation in 2017. Indian Journal of Public Health Research \& Development, 9(10), 504-8.

[8] Revitasari A. (2016). Identification of the fulfilment outpatient's medical records incompleteness based on expectancy theory motivation. Jurnal Administrasi Kesehatan Indonesia, 4(2), 86-96.

[9] Urquhart R, Kotecha J, Kendell C, Martin M, Han H, Lawson B, et al. (2018). Stakeholders' views on identifying patients in primary care at risk of dying: a qualitative descriptive study using focus groups and interviews. British Journal of General Practice, 68(674), e612-20.

[10] Franco M, Baird J, Brown LL and Overly FL. (2018). Electronic medical record in the ED: A Cross-sectional survey of resuscitation documentation practices and perceptions among emergency department clinicians. pediatric emergency care, 34(5), 303-9.

[11] Lau HS, Florax C, Porsius AJ and De Boer A. (2000). The completeness of medication histories in hospital medical records of patients admitted to general internal medicine wards. British journal of clinical pharmacology, 49(6), 597-603.

[12] Abbassi S and Tavakoli N. (2011). Quantitative analysis of medical record of patients admitted in the gharazi hospital, 1735-7853.

[13] Salazar L, Best TM and Hiestand B. (2011). Incomplete documentation of elements of Ottawa Ankle Rules despite an electronic medical record. The American journal of emergency medicine, 29(9), 999-1002.

[14] Oktoriani EN, Sutrisno J, Mayasari E and Sodik MA. (2018). Analysis of medical record complete flexibility to complete claims of health BPJS RS Baptis Kota Batu. Journal of Global Research in Public Health, 3(1), 46-53.

[15] Luthuli LP. (2017). Medical records management practices in public and private hospitals in Umhlathuze Area, South Africa. University of Zululand.

[16] Fazaeli S, Meraji M, Yousefi M and Jamali J. (2020). Comparative study of quantitative analysis indicators of inpatient medical records: Providing Analysis Tool. Journal of Modern Medical Information Sciences, 6(1). 
[17] Hussein RA, Majeed AA, Mahmoud RA, Saihoud SA and Al-Hamadi NQ. (2018). Assessment of the documentation completeness level of the medical records in Basrah General Hospital. The Medical Journal of Basrah University, $36(2), 50-9$.

[18] Rizki F, Noor NB and Mangilep AUA. (2020). Analysis of Standard Operational Procedures implementation on medical records completion at Stella Maris Hospital in Makassar, Indonesia. Enfermería Clínica, 30, 35-9.

[19] Ufitinema Y, Wong R, Adomako E, Kanyamarere L, Ntagungira EK and Kagwiza J. (2016). Increasing patient medical record completion by assigning nurses to specific patients in maternity ward at Munini hospital. On the Horizon.

[20] Akhu-Zaheya L, Al-Maaitah R and Bany Hani S. (2018). Quality of nursing documentation: Paper-based health records versus electronic-based health records. Journal of clinical nursing. 27(3-4), e578-89.

\section{How to cite this article}

Lestari W, Astuti R and Isworo S. (2020). Completeness of filling medical record documents on inpatient ward, Ungaran General Hospital-Semarang, Central Java -Indonesia. GSC Biological and Pharmaceutical Sciences, 12(1), 145-155. 